\title{
Treatment of 30 Angular Limb Deformities of the Antebrachium and the Crus in the Dog Using Circular External Fixators
}

\author{
Gian Luca Rovesti ${ }^{*}, 1$ Günter Schwarz ${ }^{2}$ and Paolo Bogoni ${ }^{3}$ \\ ${ }^{I}$ Clinica Veterinaria “M. E. Miller", Cavriago (RE), Italy \\ ${ }^{2}$ Tierklinik Hollabrunn, Hollabrunn, Austria \\ ${ }^{3}$ Ambulatorio Veterinario Associato "Bogoni-Pasotti”, Ghedi (BS), Italy
}

\begin{abstract}
Objective: To evaluate frame constructs, surgical technique, postoperative care, complications, treatment duration, and outcome of circular external fixation (CEF) for treatment of 30 antebrachial and crural angular deformities in dogs.

Study Design: Retrospective study.

Sample Population: Twenty-seven dogs with limb deformities.

Methods: Medical records of dogs that underwent surgery with CEF for angular deformities were examined for kind of deformity, frame configuration, surgical technique, treatment duration, complications and outcome.

Results: Thirty angular deformities in twenty-seven dogs were corrected using CEF. The mean time of external fixation was 72 days (median $\pm \mathrm{SD}, 65 \pm 27$ days). Minor and/or major complications were recorded in 26 out of 30 cases. Functional and cosmetic outcomes were considered excellent in 14 cases $(46.2 \%)$, good in 14 cases (46.2\%), and fair in two cases (6.6\%). Radiographic outcomes were considered excellent in 14 cases (46.2\%), good in 15 cases $(49.5 \%)$, and fair in one case $(3.3 \%)$.

Conclusion: Although complications were present in 26 out 30 cases, the functional and radiographic outcomes of circular external fixation was considered excellent or good in $92 \%$ of cases treated for limb deformities.

Clinical Relevance: CEF is an effective treatment modality for antebrachial and crural angular deformities and bone lengthening in dogs. Progressive correction is required for severe angular deformities and lengthening, thus reducing the risk of vascular and/or neurological damage to soft tissues. Complications are frequent, but can be successfully managed in most instances.
\end{abstract}

Keywords: Dog, angular deformity, limb lengthening, circular external fixation, radius-ulna, tibia.

\section{INTRODUCTION}

Angular limb deformities in the dog may result from many causes [1-6]. Complex deformities are characterized by a combination of length deficit, angular and torsional deformities, which may be followed by osteoarthritis, pain, lameness, and an obvious cosmetic disfiguration of the limb $[7,8]$. Antebrachial deformities are the most common limb malformations in dogs, being estimated at $0.74 \%$ of the appendicular skeletal disorders in a survey [9]. The primary goal of treatment is to correct angular, torsional, and length anomalies. The choice of a specific surgical procedure is closely dependent on the residual potential growth and location of the growth arrest [7, 10-16]. The correction may be achieved acutely or progressively. The choice of a specific surgical procedure is closely dependent on the residual potential growth and location of the growth arrest. If the physeal premature closure is not corrected, the angular deformity will develop until the skeletal maturity is

*Address correspondence to this author at the Ambulatorio Veterinario "M. E. Miller", Via della Costituzione, 10, 42025, Cavriago (RE), Italy; Tel: +39 0522371044; Fax: +39 0522576183; E-mail: grovesti@clinicamiller.it achieved. In young dogs with a large growth potential, ulnar or radial osteotomy and stapling are a conventional minimally invasive surgical option. In skeletally mature dogs, the surgical options are included in two groups. The first includes acute correction of limb alignment following osteotomy and stabilization by means of external coaptation, linear external fixation (LEF) or internal fixation [7, 10-16]. The acute correction has the advantage to achieve immediate postoperative (PO) limb realignment, but the constraints of surrounding soft tissues generally limit the amount of the correction that can be acutely achieved. The second group includes progressive correction of deformities using circular external fixation (CEF). The progressive technique allows gradual correction of the deformity in the PO period and slow and progressive soft tissues adaptation [7, 17-19]. The aim of this study is to evaluate the functional and cosmetic outcome of 30 cases of angular limb deformity in 27 dogs that underwent acute or progressive correction by means of CEF.

\section{MATERIALS AND METHODS}

\section{Inclusion Criteria}

Medical records and radiographs of dogs with angular limb deformities treated with CEF at the authors' institutions 
were reviewed. Inclusion criteria were unilateral or bilateral angular limb deformity causing functional and cosmetic impairment, availability of preoperative radiographs of the affect and contralateral limb, as well as PO radiographs of the treated limb, including those at the time of frame removal. Thirty limbs in 27 dogs fulfilled the criteria for inclusion in the study.

\section{Preoperative Clinical Evaluation of Torsional Deformity}

All dogs underwent a preliminary clinical examination. The presence of concurrent orthopaedic diseases and the degree of torsional deformity were appreciated at this stage. The torsional deformity was appreciated in two ways. The first evaluation was performed by flexing and extending the carpus or the tarsus of the affected leg, and observing the plane that it moved along compared to the sagittal plane. The elbow and the stifle were kept flexed at $90^{\circ}$. The second evaluation for the carpus was performed on the resting dog, maintaining the elbows in a vertical position, and comparing the toes direction from the front (Fig. 1a, b).

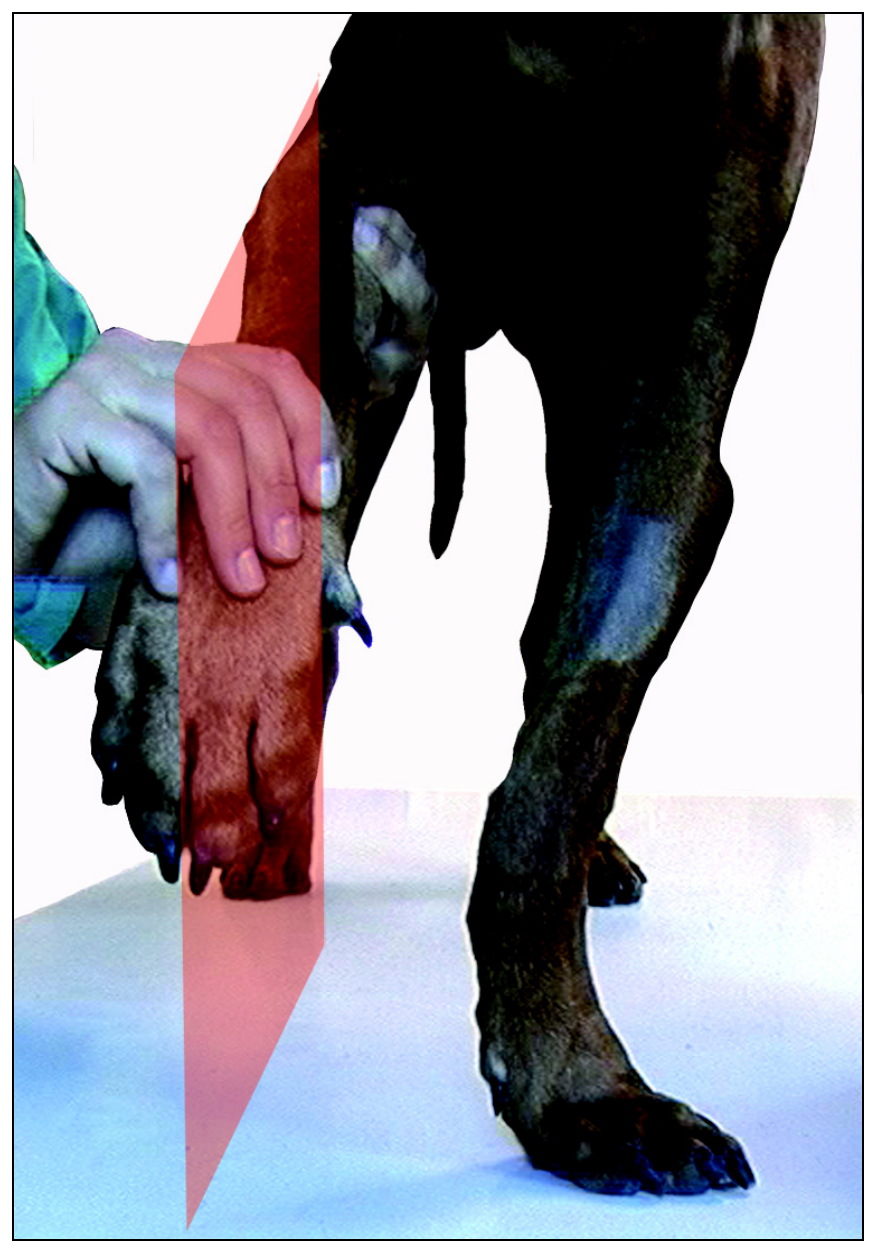

Fig. (1a). Clinical evaluation of torsional deformity. When the limb is normal, the flexion and extension of the carpus is on the same plane as for the elbow.

For the tarsus, it was performed with the dog under general anaesthesia during radiographic examination. The dog was kept in dorsal recumbency, and the stifle flexed at $90^{\circ}$. Five degrees of supinatus (external torsion) were considered a physiological deviation.

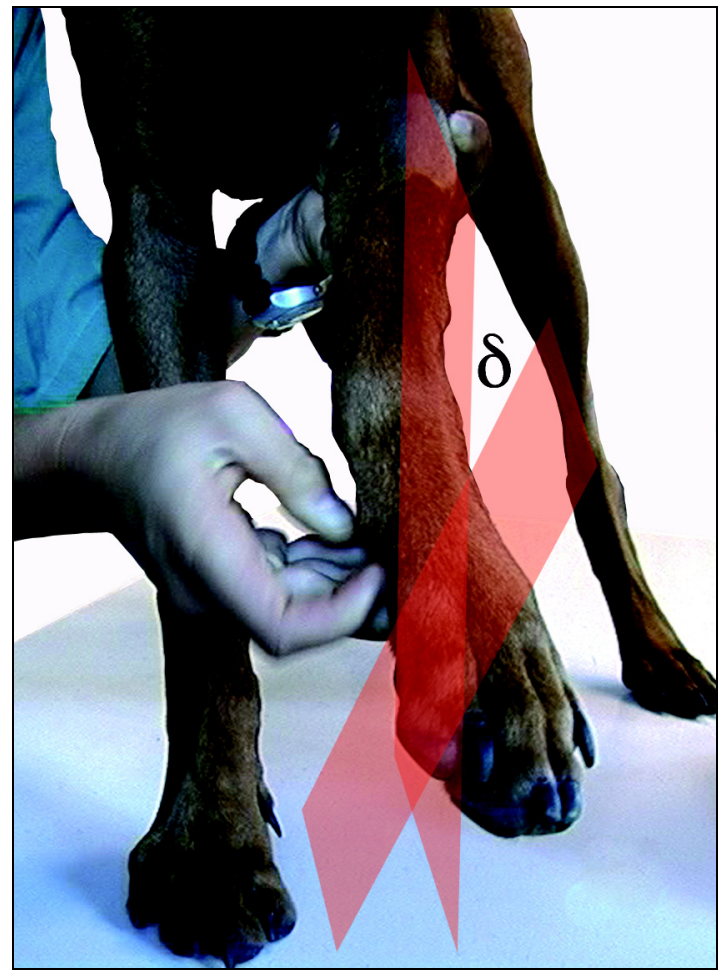

Fig. (1b). Clinical evaluation of torsional deformity. When a torsional deformity is present, the plane is rotated compared to the one of the elbow. The angle between the two planes $(\delta)$ represents the angle of torsional deformity

\section{Preoperative Radiographic Examination}

The radiographic examination was performed under general anaesthesia. Cranio-caudal (Cr-Cd) and mediolateral (ML) projections of both limbs were obtained, including the elbow and the metacarpal bones for the foreleg, while a caudo-cranial (Cd-Cr) and ML projections of both limbs were obtained, including the stifle and the metatarsal bones for the hind leg. A third radiographic projection was obtained from the affected limb, the so-called "maximum deformity" (MD) projection. This was obtained by rotating the affected limb until the deformity is almost flattened over the radiographic table, so that the maximum curvature of the deformity is outlined. Usually, this projection causes the joints adjacent to the deformity to be oblique on the radiograph, unless the deformity lies exactly on an orthogonal plane (Fig. 2a, b).

\section{Deformity Radiographic Measurement}

Following the method suggested by Marcellin-Little et al., [5] medio-lateral angulation (MLA) and cranio-caudal angulation (CCA) were calculated on radiographic films. Five degrees of valgus in the radius were considered a physiological deviation. In the tibia, every value different from zero was considered abnormal. Ten degrees of procurvatus for the radius, and ten degrees of recurvatus for the tibia were considered normal. The amplitude of the deformity that was referred to as pathological was obtained subtracting the physiological deviation to the total amount measured. The difference between the affected and the contralateral limb length represented the lengthening 


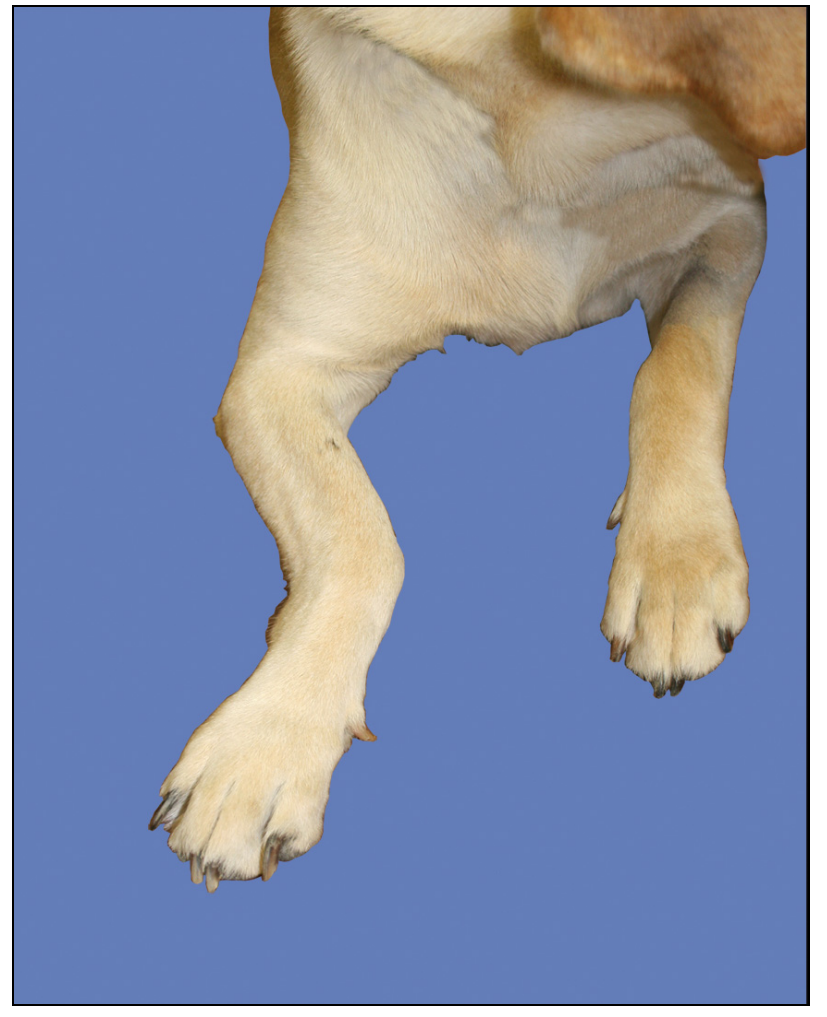

Fig. (2a). Dog's limb positioned for the maximum deformity (MD) radiographic view.

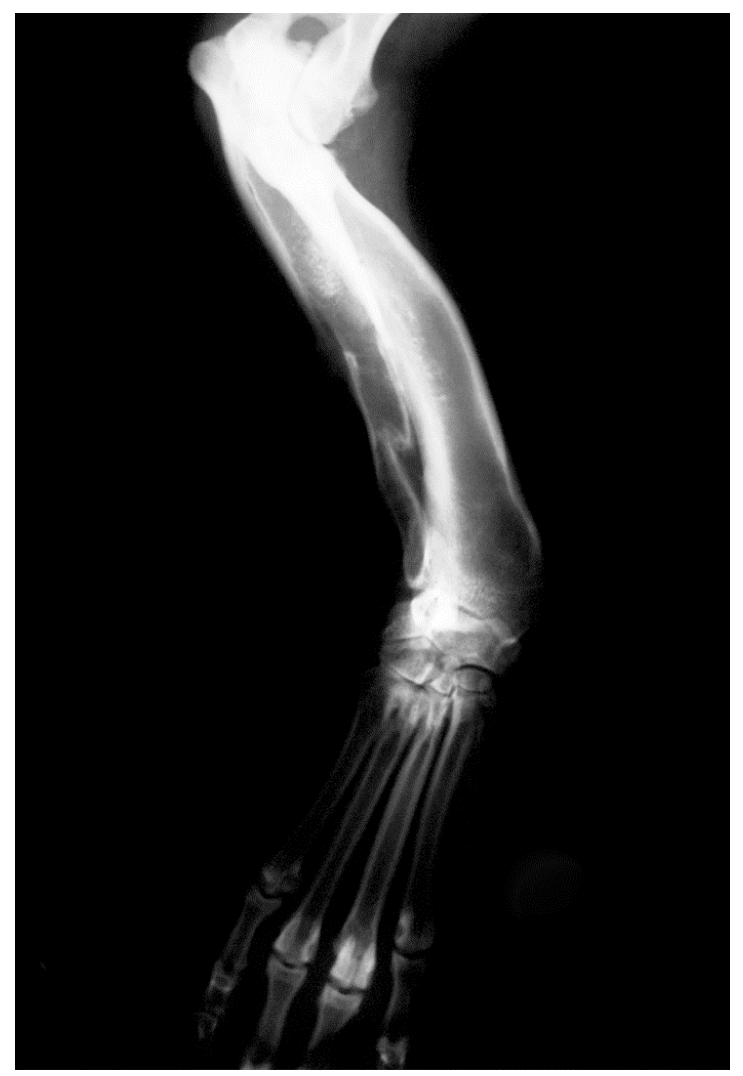

Fig. (2b). The MD radiographic view allows the calculation of the distance of the hinges from the joint.

amount to be performed in the affected limb. This calculation was not made when the limbs were bilaterally affected. The plane of deformity was calculated on the MD radiographic view, following the method described by Marcellin-Little et al. [5]. The hinges for progressive correction of the deformity should be placed on this plane.

\section{Frame Assembly}

The frame was always preassembled in the preoperative planning phase [5]. The position of the hinges was calculated as previously described by Lewis et al. [20]. The position of the hinges was such that the fulcrum, i.e. the axis of the angular movement, was tangent to the bone cortex. In this way, it is possible to achieve angular correction without lengthening [21]. Though it is possible to position the hinges offset from the bone cortex, so that angular correction and lengthening are simultaneously achieved, the strategy of the surgery was first to achieve angular correction, and then to proceed with lengthening, if required. Two fixator systems were used to treat the cases in this study: the Small Bone Fixator system (Hoffman sas, Monza, Italy) and the Universal I System (Ad Maiora, Cavriago, Italy).

\section{Surgical Procedure}

The dogs were positioned in lateral recumbency with the affected limb uppermost for the antebrachium, or in dorsal recumbency for the tibia. The surgical procedure was performed in three phases. In the first phase, an osteotomy of the ulna was performed by a caudo-lateral approach. In some cases, the surgeon elected to perform an ostectomy, when he thought that the ulnar stumps might cause interference during the later radius torsional correction. Generally, a fibular osteotomy was not performed as a specific procedure, because the fibula is easily cut together with the tibia in the distal part of the bone segment, and it usually does not interfere with intraoperative tibial rotation. In the second phase, the preassembled frame was passed over the limb and centred. The hinges, enclosed in the frame assembly, were positioned so that they lay on the plane of deformity. To check if their axis, i.e. the fulcrum, was tangent to the bone cortex, a K-wire was used to join their centres. The K-wire should contact the skin of the limb where the plane of deformity was situated. When just a torsional deformity was to be corrected, no hinges were enclosed in the frame construct, because it was always acutely corrected. The distal ring was positioned so that its plane lay parallel to that of the antebrachiocarpal joint, and the proximal one to the radio-humeral joint. In the hind limb, the landmarks were the tibio-tarsal joint and the plane perpendicular to the tibial axis, respectively. The frame was then stabilized to the bone by means of transosseous wires and threaded pins. In the third phase, a radius osteotomy, usually centred over the plane of deformity, was performed following a cranio-medial approach. In the hind limb, a tibia and fibula osteotomy was performed by a medial approach. The osteotomy was performed by an oscillating saw or by an osteotome, depending on the surgeon's preference. The torsional deformity was corrected acutely by the amount determined in the preoperative planning (Fig. 3a, b). To do this, the hinges were disconnected from the distal block, the distal stump was rotated of the amount requested, and then the hinges were connected again to the distal block in their previously calculated position. Being the distal block been rotated, the points of connection of the hinges to the distal block were different from the ones before the rotation was performed (Fig. 4a, b). 


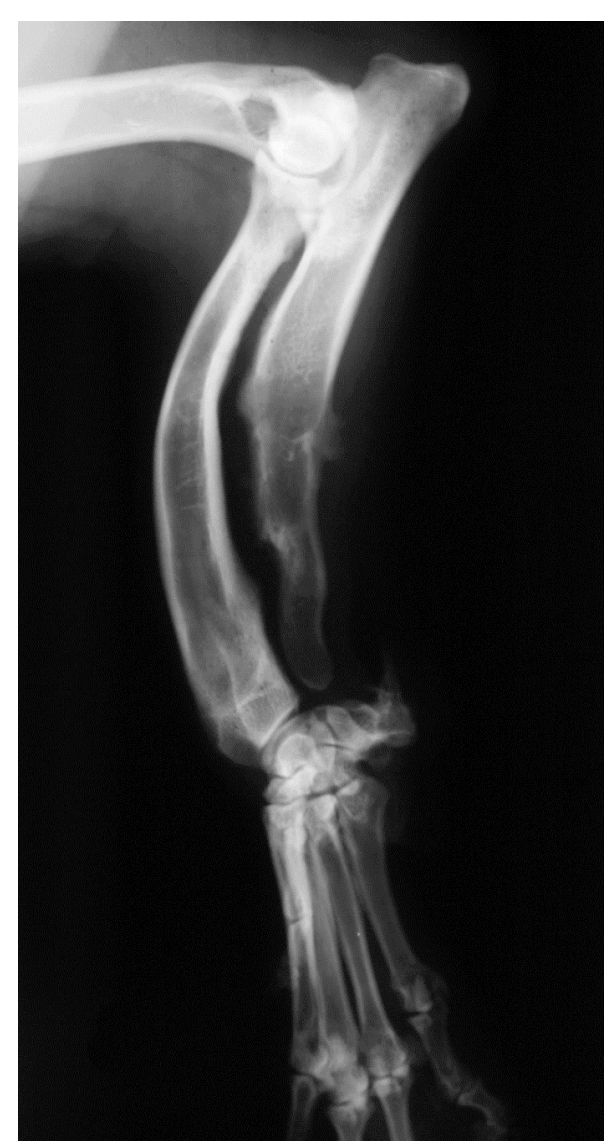

Fig. (3a). Preoperative ML radiographic view of the deformity.

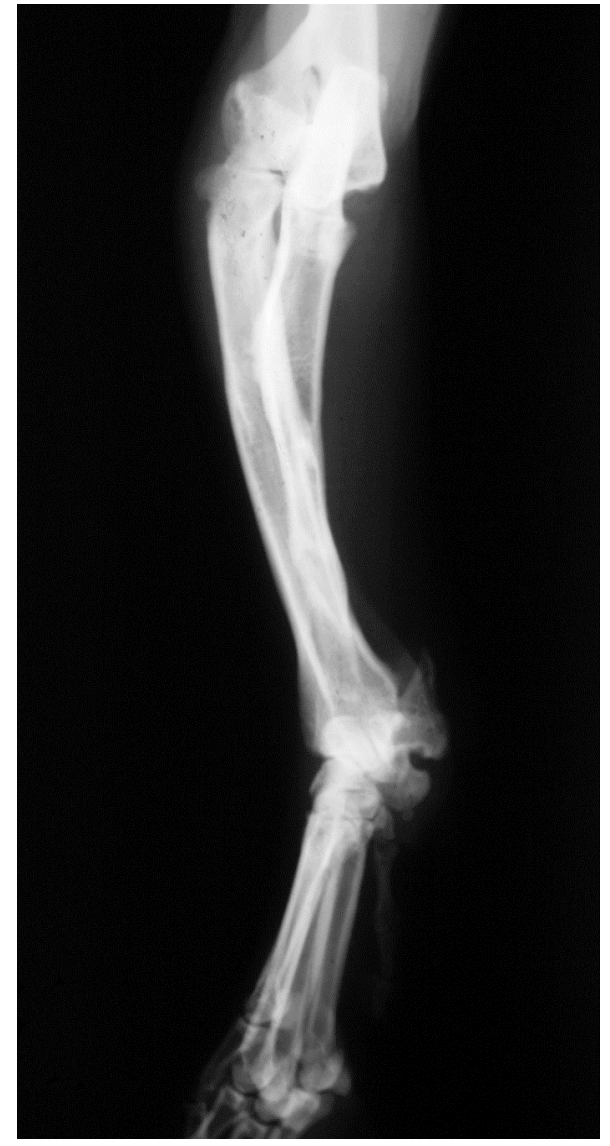

Fig. (3b). Preoperative Cr-Cd radiographic view of the deformity.

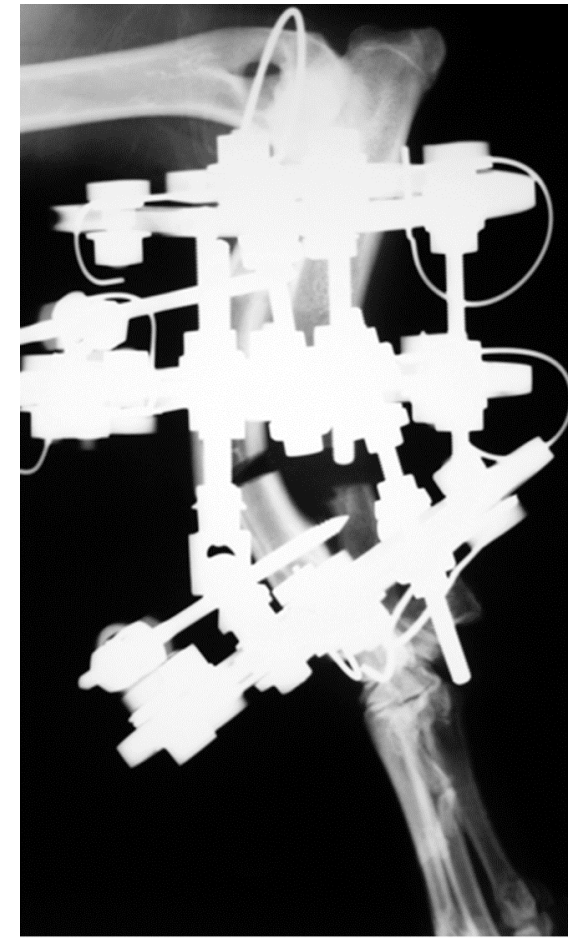

Fig. (4a). Postoperative ML radiographic view of the same limb of Fig. (3). Only the torsional deformity (supinatus) has been acutely corrected during the surgical procedure. The deformities on the frontal and sagittal plane are to be corrected progressively in the PO period.

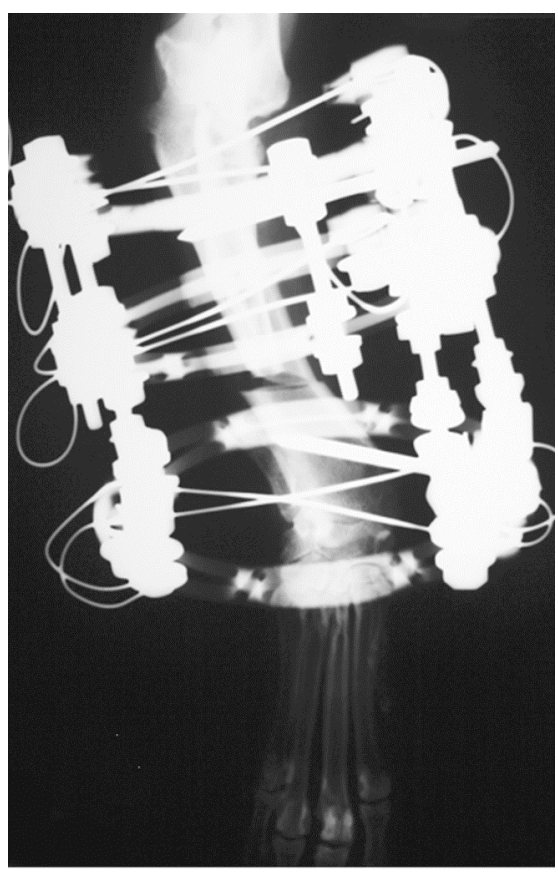

Fig. (4b). Cr-Cd radiographic view of the same limb of Fig. (3). Only the torsional deformity (supinatus) has been acutely corrected during the surgical procedure. The deformities on the frontal and sagittal plane are to be corrected progressively in the PO period.

If just a torsional deformity correction was to be performed, and hinges were not enclosed in the frame construct, the same manoeuvre was done with the threaded bars connected to the distal block. In the cases where further progressive correction was planned, the motor bar was then 
added to the frame construct, on the opposite side of the bone to that of the hinges.

\section{Correction Rate and Rhythm}

Progressive angular correction was started one to six days PO, while lengthening was started three to 21 days PO. Lengthening was started after the angular correction was considered well advanced or completed. The suggested rhythm for angular correction and for lengthening was three times per day. The amount of distraction to be performed on the motor bar to achieve $1.0 \mathrm{~mm}$ of distraction at the osteotomy site was calculated on the PO radiographs, following the method described by Marcellin-Little et al. [5] or by Lesser [22].

\section{Postoperative Management}

Postoperative management included antibiotic treatment for 5-8 days, and anti-inflammatory and analgesics drugs as required. Exercise restriction was required. Wire and pin tracts and surgical wounds were cleaned daily with povidone-iodine or clorexydine solutions. The frame was covered with a soft bandage or with a cloth sleeve. Rehabilitation included passive motion in flexion and extension of the affected limb joints for 5 to 10 minutes at least twice a day. The owners were instructed about the procedures to perform for angular correction and lengthening. Nuts on motor bar for angular correction and on threaded bars for lengthening were colour-coded to help progressive frame adjustment by the owners.

\section{Postoperative Clinical and Radiographic Examination}

Clinical PO evaluation was scheduled every 3-4 days in the immediate PO period, and then as requested. The cosmetic appearance of the limb was evaluated clinically, and signs of potential complications were appreciated. Radiographic views included $\mathrm{ML}$, and $\mathrm{Cr}-\mathrm{Cd}$ or $\mathrm{Cd}-\mathrm{Cr}$ projections. The radiographs were evaluated to estimate limb angulation and length, quality and amount of regenerate bone, and early signs of implant loosening or bone infection. As a rule, $1.0 \mathrm{~mm}$ per day of distraction at the osteotomy site was planned. Based on the quality of regenerate, it was decided if the rate should be the same, reduced or increased.

\section{Complications}

Complications were considered minor if they were managed without additional procedures under general anaesthesia, and if they delayed the course of treatment without influencing its expected outcome. Complications were considered major if they required additional procedures or substantial frame modification under general anaesthesia, and when they negatively influenced the expected outcome.

\section{Frame Removal}

The frame was removed under sedation or general anaesthesia when the osteotomy site was healed or when the regenerate was consolidated. Radiographs of the operated limb were made in the same session before and after frame removal. External coaptation was not routinely suggested after frame removal.

\section{Outcome}

Bone healing was evaluated, and radiographic results were graded as:

- Excellent: osteotomy healed and angular deformity in any plane was $<5^{\circ}$

- Good: osteotomy healed and $5^{\circ}$ to $10^{\circ}$ angular deformity in any plane was present

- Fair: osteotomy healed and $10^{\circ}$ to $30^{\circ}$ angular deformity in any plane was present

- $\quad$ Poor: osteotomy not healed or osteotomy healed and angular deformity in any plane was $>30^{\circ}$

When the deformities were multiple, they were evaluated and the result was graded as referred to the worse one.

The functional and cosmetic results were evaluated at follow up rechecks, and clinically graded [12] as:

- Excellent: functionally normal and similar in appearance to the contralateral, normal limb.

- Good: slight lameness only after extensive exercise, or minor difference from the contra lateral, normal limb.

- Fair: slight to moderate lameness but consistent weight bearing, or noticeable difference from the contra lateral, normal limb.

- Poor: non-weight bearing lameness, or marked, disfigured alteration from the contralateral, normal limb.

When a contralateral, normal limb was not present, the evaluation was done comparing the affected limb with a normal-appearing dog limb.

\section{RESULTS}

This study included 30 limbs in 27 dogs surgically treated for angular limb deformities by means of CEF. Twenty-seven cases involved the radius-ulna and three cases the tibia. Twenty-four dogs presented deformity in one limb, two in the forelimb bilaterally, and one in the hind limb bilaterally. Data about the dogs and kind of deformity are summarized in Table $\mathbf{1}$.

The limb affected was in 14 cases the right forelimb, in 13 cases the left forelimb, in two cases the right hind limb and in one case the left hind limb. The mean valgus deformity was $22.7^{\circ}$ (range, $10^{\circ}$ to $42^{\circ}$, median $21^{\circ}$ ). The varus deformity was present in two cases (case 16 and 26, with $40^{\circ}$ and $10^{\circ}$, respectively). The mean of supinatus deformity was $39.4^{\circ}$ (range, $15^{\circ}$ to $75^{\circ}$, median $35^{\circ}$ ). The mean of procurvatus deformity was $28.8^{\circ}$ (range, $13^{\circ}$ to $53^{\circ}$, median $30^{\circ}$ ). The recurvatus deformity $\left(21^{\circ}\right)$ was present in only one case (case 16), and was associated to radius-ulna shortening, carpus varus and pes supinatus. Pronatus deformity was not diagnosed in this case series. The mean of shortening of the affected bone was $16.4 \mathrm{~mm}$ (range, 1 to 45 , median $14 \mathrm{~mm}$ ). In 27 procedures the deformity was corrected using the Small Bone Fixator system (Hoffman sas, Monza, Italy), and in three the Universal I System (Ad Maiora, Cavriago, Italy). The frame structures are summarized in Table 2. 
Table 1. Data About Signalment, Affected Limb and Kind of Deformity of the Dogs with Angular Deformities

\begin{tabular}{|c|c|c|c|c|c|c|}
\hline Case \# & Breed & Affected Limb & Sex & Age at Surgery (Months) & Weight (Kg) & Kind of Deformity \\
\hline 1 & Mongrel & RFL & FS & 21 & 20 & RU, Sh, CV, PS \\
\hline 2 & Rottweiler & LFL & M & 8 & 31 & EI, RU, Sh, PS \\
\hline 3 & Mongrel & LFL & M & 10 & 21 & RU, Sh, CV, PS \\
\hline 4 & German Shepherd & RFL & M & 18 & 42 & RU, Sh, RP, CV \\
\hline 5 & Bull Mastiff & LFL & M & 5,5 & 35 & $\mathrm{CV}, \mathrm{PS}$ \\
\hline 6 & Mongrel & LFL & M & 10 & 10 & RU, Sh, RP, CV, PS \\
\hline 7 & Pitbull & RFL & FS & 8 & 24 & RU, Sh, RP, CV, PS \\
\hline 8 & Doberman & RFL & $\mathrm{F}$ & 26 & 23 & $\mathrm{RP}, \mathrm{CV}, \mathrm{PS}$ \\
\hline 9 & Mongrel & RFL & $\mathrm{F}$ & 54 & 11 & RU, Sh, RP, CV, PS \\
\hline 10 & English Pointer & RHL & $\mathrm{F}$ & 7 & 14 & TV, PS \\
\hline 11 & Bull Mastiff & LHL & $\mathrm{F}$ & 11 & 39 & PS \\
\hline 12 & Bull Mastiff case \#11 & RHL & & 14 & 42 & PS \\
\hline 13 & Italian Bloodhound & LFL & M & 8 & 25 & $\mathrm{RP}, \mathrm{CV}, \mathrm{PS}$ \\
\hline 14 & Italian Bloodhound case \#13 & RFL & & 21 & 31 & $\mathrm{RP}, \mathrm{CV}, \mathrm{PS}$ \\
\hline 15 & Pinscher & RFL & M & 8 & 4 & $\mathrm{RP}, \mathrm{CV}, \mathrm{PS}$ \\
\hline 16 & English Setter & LFL & $\mathrm{F}$ & 20 & 14 & RU, Sh, RR, CV, PS \\
\hline 17 & Rhodesian Ridgeback & LFL & M & 10 & 30 & RU, Sh, RP, CV, PS \\
\hline 18 & German Shepherd & LFL & M & 17 & 35 & $\mathrm{CV}, \mathrm{PS}$ \\
\hline 19 & Mongrel & LFL & $\mathrm{F}$ & 18 & 15 & $\mathrm{RP}, \mathrm{CV}, \mathrm{PS}$ \\
\hline 20 & German Shepherd & LFL & M & 10 & 29 & $\mathrm{CV}$ \\
\hline 21 & Bernese Mountain Dog & RFL & $\mathrm{F}$ & 7,5 & 30 & RU, Sh, RP, CV, PS \\
\hline 22 & Mongrel & RFL & M & 7 & 22 & RU, Sh, RP, CV, PS \\
\hline 23 & Mongrel & LFL & $\mathrm{MN}$ & 7 & 15 & RU, Sh, RP, CV, PS \\
\hline 24 & Hovawart & LFL & M & 10 & 36 & $\mathrm{RP}, \mathrm{CV}, \mathrm{PS}$ \\
\hline 25 & Mongrel & RFL & FS & 19 & 21 & $\mathrm{RP}, \mathrm{CV}, \mathrm{PS}$ \\
\hline 26 & Boxer & RFL & $\mathrm{F}$ & 7 & 21 & $\mathrm{RU}, \mathrm{Sh}, \mathrm{RP}, \mathrm{CVa}$ \\
\hline 27 & Mongrel & RFL & $\mathrm{MN}$ & 36 & 11 & $\mathrm{RP}, \mathrm{CV}, \mathrm{PS}$ \\
\hline 28 & Mongrel case\#27 & LFL & & 38 & 11 & $\mathrm{RP}, \mathrm{CV}, \mathrm{PS}$ \\
\hline 29 & Mongrel & RFL & $\mathrm{MN}$ & 8 & 16 & $\mathrm{RP}, \mathrm{CV}, \mathrm{PS}$ \\
\hline 30 & Argentine Dogo & RFL & $\mathrm{MN}$ & 28 & 55 & $\mathrm{RP}, \mathrm{CV}$ \\
\hline & & \multicolumn{2}{|c|}{ Average } & 15,7 & 24,4 & \\
\hline & & \multicolumn{2}{|c|}{ Median } & 10,0 & 22,5 & \\
\hline
\end{tabular}

Legend: $\mathrm{RFL}=$ right forelimb, $\mathrm{LFL}=$ left forelimb, $\mathrm{RHL}=$ right hind limb, $\mathrm{LHL}=$ left hind limb, $\mathrm{RU}=$ radius-ulna, $\mathrm{CV}=$ carpus valgus, $\mathrm{PS}=$ pes supinatus, $\mathrm{RP}=$ radius procurvatus, $\mathrm{RR}=$ radius recurvatus, $\mathrm{TV}=$ tarsus valgus, $\mathrm{Sh}=$ shortening, $\mathrm{EI}=$ elbow incongruency, $\mathrm{CVa}=$ carpus varus .

\section{Surgical Procedure}

An osteotomy was performed in 18 cases on both the radius and ulna, in 8 cases on the radius, and in 3 cases on the tibia and fibula. In case $\# 5$ the technique carried out during the first procedure was a progressive deformity correction by means of physis distraction technique without osteotomy, i.e. distraction epiphysiolysis or chondrodiatasis technique $[19,23-26]$. During the revision surgery of this case, a 25-mm long ulnar ostectomy, without a radial osteotomy, was performed. When the osteotomy was performed on the radius, it was associated with ulnar ostectomy. The length of the ulnar segment removed was 10 $\mathrm{mm}$ in one, $15 \mathrm{~mm}$ in three, and $20 \mathrm{~mm}$ in four cases. The oscillating saw was used in 25 surgeries and the osteotome in five. The osteotomies were performed at level of the distal third of the bone. The supinatus deformity was always corrected acutely during surgery, while the correction of valgus, varus, procurvatus and shortening deformities was 
Table 2. Frames Structure

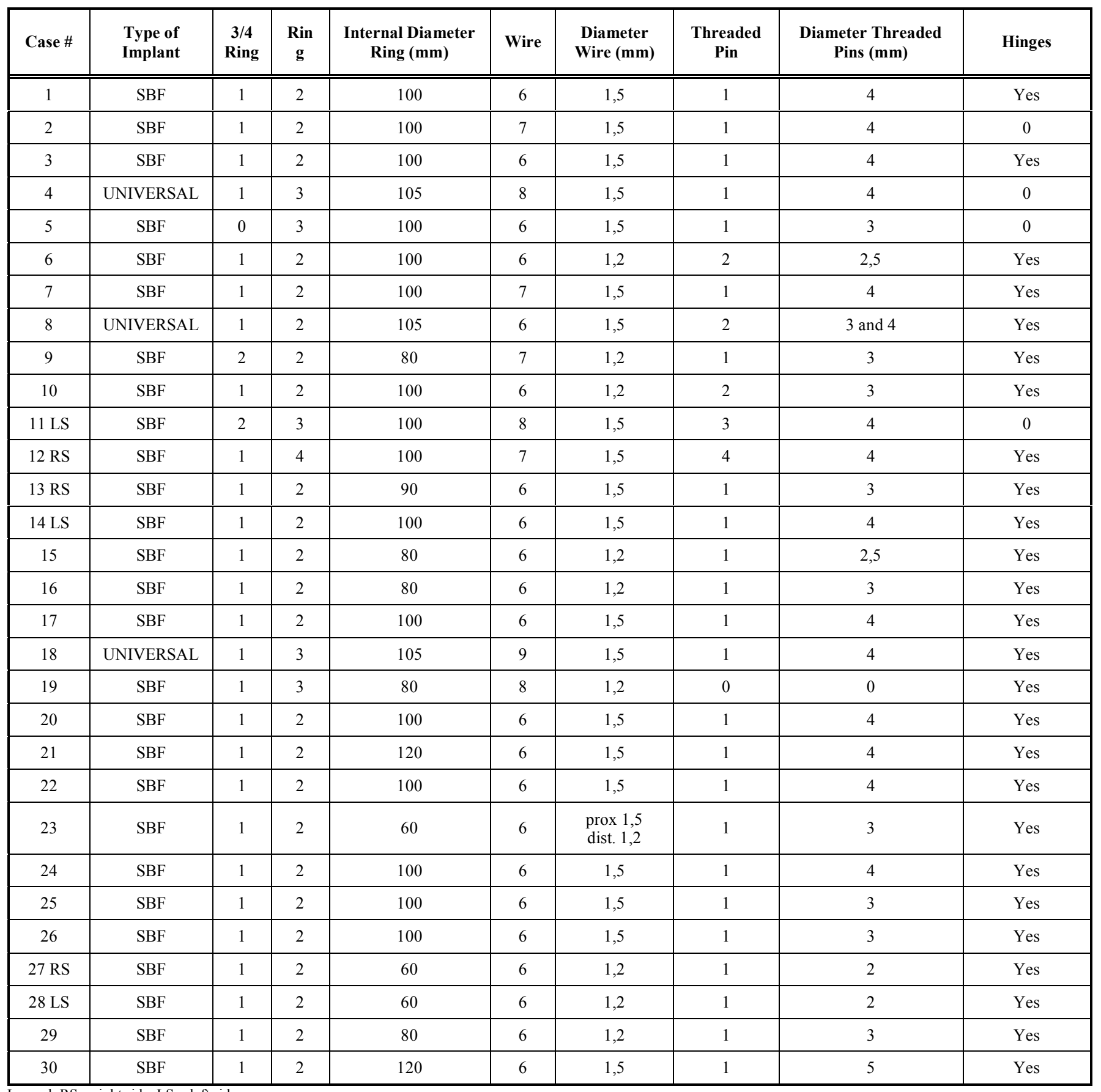

carried out progressively in the PO period. Latency period, rhythm, time of angular deformity correction, lengthening and overall fixation of each case are summarized in Table 3.

Mean time to achieve clinical limb realignment was 13 days [range, 0 (acute correction) to 33, median 14]. The mean lengthening performed was $19.7 \mathrm{~mm}$ (range, 10 to 39, median 16). Mean time to complete angular and lengthening correction (total time of correction) was 19 days (range, 0 to 59 , median 18). The mean distraction index [27] was of 0.44 months $/ \mathrm{cm}$ (range, 0.13 to 0.96 , median 0.37 ). The mean maturation index [27] was of 1.28 months/cm (range, 0.3 to 2.7 , median 1.08). The frame was removed when the bone regenerate was judged radiographically consolidated. The mean time of external fixation was 72 days (range, 39 to 143 , median 65). The mean external fixator index [27] was $1.84 \mathrm{month} / \mathrm{cm}$ (range, 0.39 to 3.5 , median 1.4). In case \#18, due to the dog exuberant behaviour, a cast was applied for 30 days after frame removal. The overall mean time for bone consolidation was 50 days (range, 15 to 122 , median 45 ). In 10 cases where angular limb deformity and shortening were corrected, the mean time for bone regenerate consolidation was 56 days (range, 30 to 81 , median 57). In the 20 cases where only the angular deformity was corrected, either acutely or progressively, the mean time for bone consolidation was 47 days (range, 15 to 122, median 45). 
Tables 3. Times for Angular Correction, Lengthening, and Bone Healing of the Operated Limbs

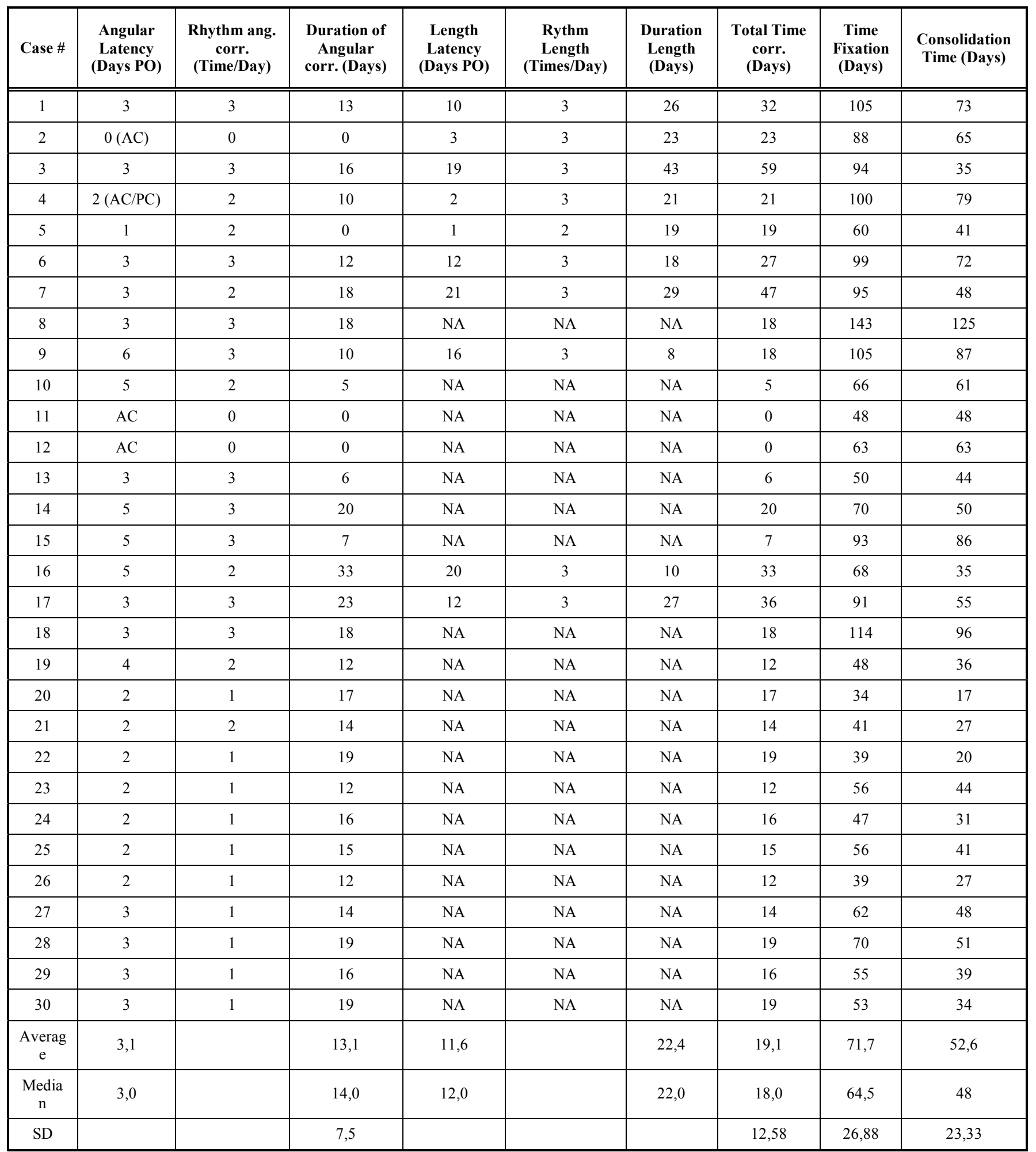

Legend: $\mathrm{AC}=$ acute correction, $\mathrm{PC}=$ progressive correction, $\mathrm{NA}=$ not applicable.

In all cases the frame was removed when the bone consolidation was considered complete.

\section{Postoperative Management}

Mean number of clinical and radiographic rechecks was seven (range, 4 to 15 , median 6). No complications were recorded in four cases $(13.3 \%)$, minor complications in 10 cases $(33.3 \%)$, major complications in six cases $(20 \%)$, and both minor and major complications in 10 cases $(33.3 \%)$.

\section{Minor Complications}

The most common minor complication was represented by wire tracts inflammation and serum discharge $(\mathrm{n}=18$, 


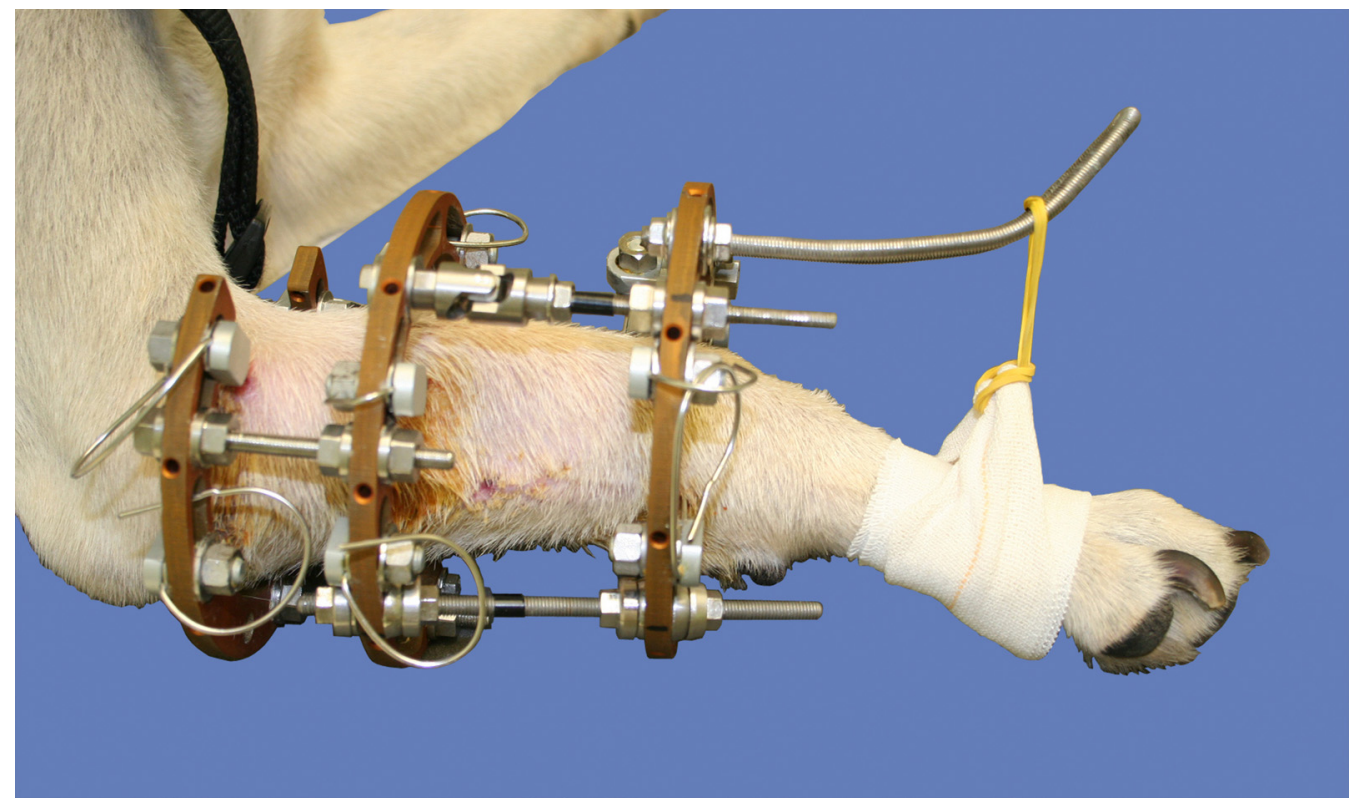

Fig. (5). Positioning of the stirrup with elastic bands used to maintain the carpus in extension during the lengthening phase.

$60 \%)$, purulent discharge $(\mathrm{n}=4,13.3 \%)$ and carpus contracture. Carpus contracture $(n=4,13.3 \%)$ was managed by physiotherapy, and by a stirrup with elastic bands to counteract flexion contracture. A threaded bar bent in " $U$ " fashion, connected by nuts to the most distal ring of the frame, was used as a stirrup. The bar was placed in the cranial aspect of the leg, and it was extended to the level of metacarpo-phalangeal joints. The paw was bandaged and connected to the bar by elastic bands, tensioned as needed to keep the carpus extended (Fig. 5).

This forced the carpus in extension in a continuous way, thus counteracting the flexion contracture. At least two times per day, the elastic bands were disconnected from the stirrup and physiotherapy was performed. Analgesics and/or non steroidal anti-inflammatory drugs where administered as required to put pain under control, thus increasing dogs' compliance to physiotherapy and ameliorating the use of the limb. Minor complications and treatment are summarized in Table 4.

\section{Major Complications}

Early wire or pin breakage or the need to add one or more wires or threaded pins, to achieve more frame stability or for its modification and residual torsional deformity (cases \# 8,11, 12, 18, 25, 27, 28), was the most frequent major complications. The residual torsional deformity was, in all cases, corrected under general anaesthesia, in acute fashion without frame modification. Complications are summarized in Table 4.

Twenty-three out of 30 cases required hospitalization. Mean duration of hospitalization was 6 days (range, 2 to 24, median 4). Reasons for hospitalization are illustrated in Table 5.

\section{Outcome}

Functional and cosmetic outcomes were judged as excellent in 14 cases $(46.2 \%)$, good in 14 cases $(46.2 \%)$, and fair in two cases $(6.6 \%)$. Radiographic outcomes were judged as excellent in 14 cases $(46.2 \%)$, good in 15 cases $(49,5 \%)$, and fair in one case $(3.3 \%)$.

Residual deformities were in average 3.4 degrees (median 2.0, SD \pm 4.1 ) for valgus and $1.65 \%$ of radial length. Values of radiographic deformities, length deficit and radiographic outcomes are illustrated in Table 6.

\section{DISCUSSION}

When the deformity does not include a significant length deficit, or when angulation and torsion are mild, a therapeutic choice can be a surgical technique based on acute correction and internal or external static fixation [7, 10-16]. Distraction osteogenesis by CEF is suited to treat complex deformities, and significant length deficit [6, 28, 29]. The deformity and length deficit of the affected limb were measured on $\mathrm{Cr}-\mathrm{Cd}, \mathrm{Cd}-\mathrm{Cr}$ and $\mathrm{ML}$ views, and then compared with data collected on films of the non-affected limb. The MD radiographic view allows the calculation of the deformity plane and the distance of the hinges from the joints. This projection is somewhat different in calculating the plane of deformity compared with was previously described. When the plane of deformity was calculated on the orthogonal projections, the $\mathrm{Cr}-\mathrm{Cd}$ or $\mathrm{Cd}-\mathrm{Cr}$ ones were used, instead of the ML ones. This was because it was felt that the deformities on the sagittal plane have less clinical impact than those on the frontal plane [16]. The MD projection represents the result of both the deformities, and it is, in our experience, a good reference for calculating where to put the hinges. This may not be the case where multiple centres of deformity are present in the same bone. Preassembling of the frame resulted in a spare of intraoperative time, and allowed the surgeon to evaluate potential intraoperative problems beforehand. Significant differences between the two CEF systems were not found in this study. The reduced number of cases treated with the Universal I System (Ad Maiora, Cavriago, Italy) system I may not be enough to show potential pitfalls of the system. 
Tables 4. Major and Minor Complication

\begin{tabular}{|c|c|c|c|c|}
\hline Case & Minor Complication & Treatment & Major Complication & Treatment \\
\hline 1 & wire tracts serous discharge & $\mathrm{CA}$ & None & None \\
\hline 2 & $\begin{array}{l}\text { wire tracts serous discharge, } 1 \text { wire tract } \\
\text { deep infection }\end{array}$ & $\mathrm{CA}, \mathrm{AB}$ & 3 broken wires & wires replacement \\
\hline 3 & carpus flexion contracture & $\mathrm{S}$ & None & None \\
\hline 4 & wire tracts serous discharge & $\mathrm{CA}$ & 4 broken wires & wires replacement \\
\hline 5 & None & None & physis distraction technique failed & $\begin{array}{l}\text { revision surgery with frame } \\
\text { modification and ulnar ostectomy }\end{array}$ \\
\hline 6 & None & None & $\begin{array}{l}\text { delayed regenerate consolidation, } \\
\text { osteolysis around a threaded pin }\end{array}$ & $\begin{array}{l}\text { autogenous cancellous bone graft pin } \\
\text { replacement }\end{array}$ \\
\hline 7 & wire tracts serous discharge & CA & $\begin{array}{l}2 \text { threaded pins added and hinges position } \\
\text { modified }\end{array}$ & $\begin{array}{l}2 \text { threaded pins added and hinges } \\
\text { position modified }\end{array}$ \\
\hline 8 & wire tracts serous discharge & $\mathrm{CA}$ & residual supinatus & acute correction \\
\hline 9 & $\begin{array}{l}\text { wire tracts serous discharge, carpus } \\
\text { flexion contracture }\end{array}$ & $\mathrm{CA}, \mathrm{S}$ & None & None \\
\hline 10 & wire tracts serous discharge & $\mathrm{CA}$ & None & None \\
\hline 11 & None & None & residual supinatus & acute correction \\
\hline 12 & None & None & residual pronatus & acute correction \\
\hline 13 & wire tracts serous discharge & $\mathrm{CA}$ & None & None \\
\hline 14 & wire tracts serous discharge & CA & None & None \\
\hline 15 & None & None & None & None \\
\hline 16 & wire tracts serous discharge & $\mathrm{CA}$ & $\begin{array}{l}\text { radio-carpal subluxation occurred during } \\
\text { lengthening phase }\end{array}$ & $\begin{array}{l}1 \text { ring added for subluxation stopping } \\
\text { lengthening procedure }\end{array}$ \\
\hline 17 & $\begin{array}{l}\text { wire tracts serous discharge, carpus } \\
\text { flexion contracture }\end{array}$ & $\mathrm{CA}, \mathrm{S}$ & $\begin{array}{l}\text { early regenerate consolidation, with } \\
\text { incomplete deformity correction }\end{array}$ & $\begin{array}{l}\text { New distal metaphyseal radio-ulnar } \\
\text { osteotomy and acute correction }\end{array}$ \\
\hline 18 & $\begin{array}{c}\text { wire tracts serous discharge, } 1 \text { wire tract } \\
\text { deep infection }\end{array}$ & $\mathrm{CA}, \mathrm{AB}$ & $\begin{array}{l}\text { haemorrhage from a wire tract, } \\
\text { residual supinate }\end{array}$ & $\begin{array}{l}\text { wire change required } \\
\text { acute correction }\end{array}$ \\
\hline 19 & $\begin{array}{l}1 \text { wire tract deep infection, } 1 \text { wire } \\
\text { removal }\end{array}$ & $\mathrm{AB}$ & None & None \\
\hline 20 & None & None & None & None \\
\hline 21 & wire tract serous discharge & $\mathrm{CA}$ & None & None \\
\hline 22 & $\begin{array}{l}\text { wire tracts serous discharge - carpus } \\
\text { flexion contracture }\end{array}$ & $\mathrm{CA}, \mathrm{S}$ & None & None \\
\hline 23 & None & None & None & None \\
\hline 24 & $\begin{array}{l}1 \text { wire tract deep infection, wire tracts } \\
\text { serous discharge }\end{array}$ & $\mathrm{CA}, \mathrm{AB}$ & None & None \\
\hline 25 & wire and pin tracts serous discharge & $\mathrm{CA}$ & residual supinatus & acute correction \\
\hline 26 & wire tract serous discharge & $\mathrm{CA}$ & $\begin{array}{l}\text { premature arrest lengthening, insufficient } \\
\text { lengthening achieved }\end{array}$ & None \\
\hline 27 & wire tract serous discharge & $\mathrm{CA}$ & residual supinatus & acute correction \\
\hline 28 & None & None & residual supinatus & acute correction \\
\hline 29 & None & None & None & None \\
\hline 30 & None & None & pin tract deep infection & pin remove and $\mathrm{AB}$ \\
\hline
\end{tabular}

Legend: $\mathrm{CA}=$ daily cleaning and reducing activity, $\mathrm{AB}=$ systemic antibiotic therapy, $\mathrm{S}=$ stirrup.

The correct positioning of the hinges represented a major intraoperative problem. Though the preoperative calculation may be very accurate, it is not always easy to position the hinges in the exact site theoretically scheduled. This may 
Table 5. Cause of Hospitalization

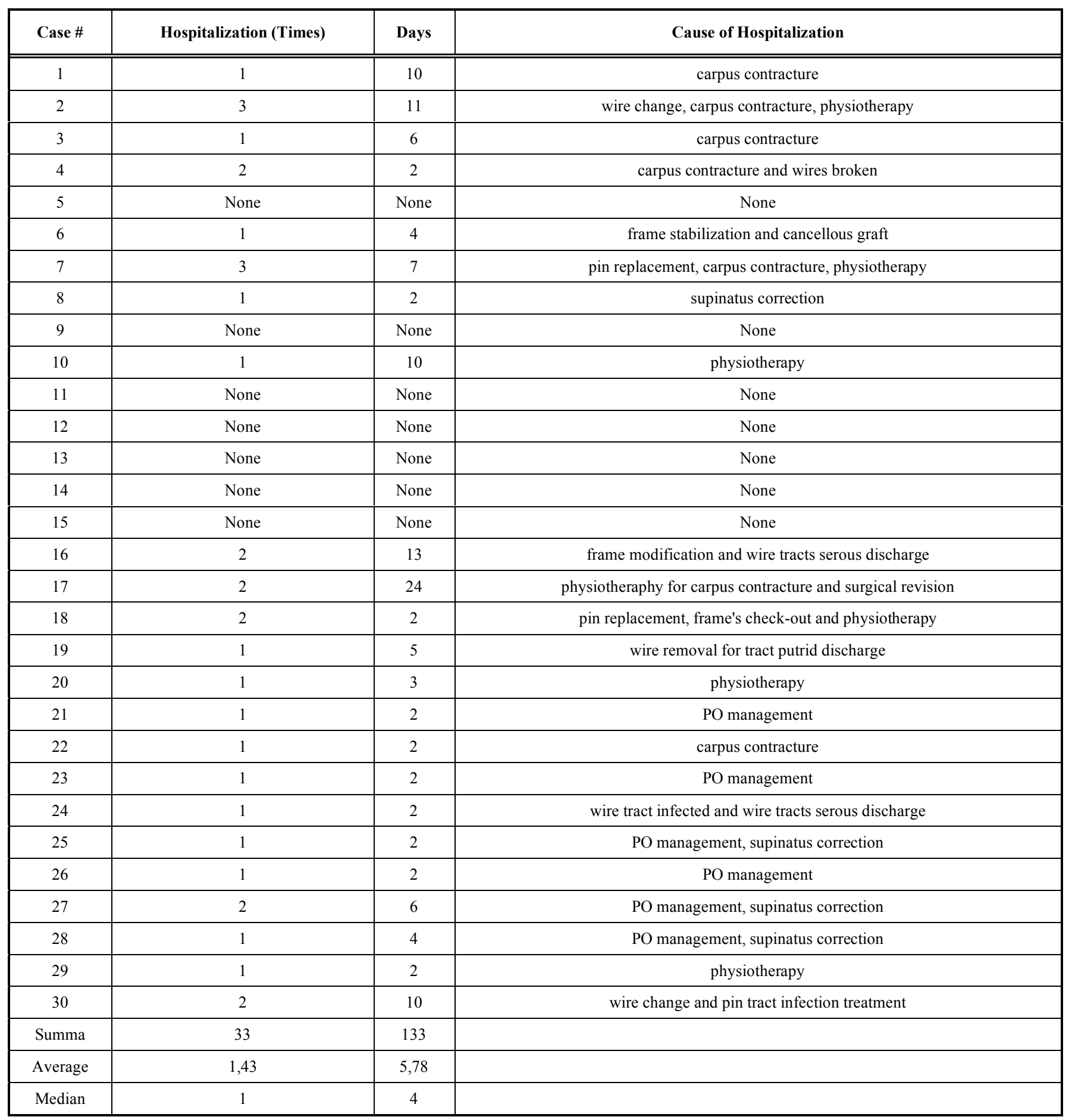

lead to an unpredictable correction, with the need of changing the hinges position. Intraoperative fluoroscopy was used in 18 surgery sessions, in order to better visualize the hinges position, to help in performing the osteotomy/ostectomy, and to make the transosseous wires exact positioning and direction easier. The osteotomy of the radius and tibia was performed after the frame stabilisation to the bone, though it was a bit difficult because of the spatial interference by the frame with the oscillating saw. This allows a more precise frame positioning over the limb, following the preoperative planning, if compared to positioning the frame when the osteotomy is already done, and the bone segments are much more instable. The osteotomy of radius or tibia was performed by an oscillating saw in 25 cases, in combination with a copious cooling irrigation with saline. In these cases we did not record negative effects on osteogenesis, as reported in other works $[5,6,18,28]$. The only case of delayed union (case \#6) had the osteotomy performed using an osteotome, though it was not a corticotomy. A latency of 1 to 6 days was used in this study, and was based on the 
Table 6. Preoperative and Postoperative Limb's Radiographic Values and Functional Outcomes

\begin{tabular}{|c|c|c|c|c|c|c|c|c|c|c|}
\hline Case \# & $\begin{array}{c}\text { Affected } \\
\text { Bone } \\
\text { Degrees } \\
\text { of } \\
\text { Valgus }\end{array}$ & $\begin{array}{c}\text { Affected } \\
\text { Bone } \\
\text { Degrees } \\
\text { of } \\
\text { Varus }\end{array}$ & \begin{tabular}{|} 
Affected \\
Bone \\
Degrees \\
of \\
Supinatus
\end{tabular} & $\begin{array}{l}\text { Affected Bone } \\
\text { Degrees of } \\
\text { Procurvatus }\end{array}$ & $\begin{array}{c}\text { Shortening } \\
\text { mm }\end{array}$ & $\begin{array}{c}\text { Rx Outcome } \\
\text { Degrees of } \\
\text { Residual Valgus }\end{array}$ & $\begin{array}{c}\text { Rx } \\
\text { Outcome } \\
\text { Degrees of } \\
\text { Residual } \\
\text { Procurvatus }\end{array}$ & \begin{tabular}{|c} 
Rx Outocome \\
mm \\
Shortening
\end{tabular} & $\begin{array}{c}\text { Radiographic } \\
\text { Outcome }\end{array}$ & $\begin{array}{c}\text { Functional } \\
\text { and } \\
\text { Cosmetic } \\
\text { Outcome }\end{array}$ \\
\hline 1 & 24 & 0 & 20 & 15 & 26 & 0 & 5 & 1 & Good & Good \\
\hline 2 & 11 & 0 & 25 & 13 & 18 & 0 & 1 & 2 & Excellent & Excellent \\
\hline 3 & 30 & 0 & 50 & 30 & 45 & 1 & 7 & 6 & Good & Excellent \\
\hline 4 & 10 & 0 & NP & 30 & 30 & 2 & 4 & 4 & Excellent & Good \\
\hline 5 & 22 & 0 & 15 & 22 & $\mathrm{NP}$ & 0 & 5 & 0 & Good & Good \\
\hline 6 & 24 & 0 & 20 & 24 & 11 & 0 & 3 & 1 & Excellent & Excellent \\
\hline 7 & 38 & 0 & 75 & 53 & 15 & 0 & 2 & 5 & Excellent & Good \\
\hline 8 & 14 & 0 & 45 & 42 & 6 & 2 & 6 & 1 & Good & Good \\
\hline 9 & 28 & 0 & 45 & 32 & 13 & 3 & 0 & 3 & Excellent & Excellent \\
\hline 10 & 16 & 0 & 30 & NP & 5 & 0 & 0 & 0 & Excellent & Excellent \\
\hline 11 & NP & 0 & 45 & NP & NP & 0 & 0 & 0 & Excellent & Excellent \\
\hline 12 & 12 & 0 & 45 & NP & $\mathrm{NP}$ & 0 & 0 & 0 & Excellent & Excellent \\
\hline 13 & 28 & 0 & 35 & 32 & $\mathrm{NP}$ & 3 & 0 & 0 & Excellent & Good \\
\hline 14 & 20 & 0 & 30 & 42 & NP & 2 & 8 & 0 & Good & Fair \\
\hline 15 & 18 & 0 & 25 & 18 & 1 & 0 & 0 & 0 & Excellent & Excellent \\
\hline 16 & NP & 40 & 60 & NP & 27 & 0 & 0 & 2 & Excellent & Good \\
\hline 17 & 30 & 0 & 30 & 43 & 24 & 4 & 3 & 8 & Excellent & Good \\
\hline 18 & 14 & 0 & 30 & 14 & 1 & 2 & 2 & 0 & Excellent & Good \\
\hline 19 & 20 & 0 & 50 & 38 & 5 & 8 & 8 & 0 & Good & Good \\
\hline 20 & 32 & 0 & NP & NP & 31 & 6 & 0 & 8 & Good & Good \\
\hline 21 & 29 & 0 & 27 & 29 & 16 & 9 & 0 & 1 & Good & Excellent \\
\hline 22 & 30 & 0 & 30 & 26 & 19 & 4 & 6 & 2 & Good & Good \\
\hline 23 & 21 & 0 & 40 & 28 & 7 & 8 & 2 & 4 & Good & Excellent \\
\hline 24 & 14 & 0 & 32 & 20 & 10 & 7 & 6 & 4 & Good & Good \\
\hline 25 & 42 & 0 & 60 & 33 & 6 & 18 & 12 & 4 & Fair & Good \\
\hline 26 & NP & 10 & $\mathrm{NP}$ & 21 & 36 & 0 & 0 & 24 & Excellent & Excellent \\
\hline 27 & 18 & 0 & 75 & 36 & NP & 8 & 5 & 0 & Good & Excellent \\
\hline 28 & 18 & 0 & 75 & 30 & NP & 8 & 6 & 0 & Good & Excellent \\
\hline 29 & 32 & 0 & 35 & 32 & NP & 6 & 8 & 0 & Good & Excellent \\
\hline 30 & 20 & 0 & 15 & 18 & 9 & 3 & 8 & 0 & Good & Fair \\
\hline Average & 22,7 & & 39,4 & 28,84 & 16,4 & 3,4 & 3,5 & 2,66 & 14 Excellent & 14 Excellent \\
\hline Median & 21 & & 35 & 30 & 14 & 2 & 3 & 1 & 15 Good & 14 Good \\
\hline SD & & & & & & 4,1 & & 4,7 & 1 Fair & 2 Fair \\
\hline
\end{tabular}

dog's age, on the osteotomy location (diaphyseal vs metaphyseal), and on PO limb's and dog's conditions. The worse are the biological conditions after the surgery, the longer should be the latency period. When angular deformity was combined with shortening, the progressive correction for angular deformity started first, and when the bone axis was considered restored enough, lengthening was started. In our experience, many potential major complications may preclude achieving the scheduled lengthening. If lengthening is to be stopped for any reason before it is completed, at least the angular deformity is corrected yet. In this study, the rhythm used to correct angular deformities ranged from one to three times per day. In 10 cases with limb shortening, the rhythm was two and three times per day. Distraction osteogenesis was always obtained, despite the fact that at least three times per day should be the minimum rhythm required, and the results are similar to the ones reported in other studies [20, 28, 30, 31].

The complications encountered in this study were many. Wire and pin discharge was the more common, and it is often associated with excessive skin and deeper soft tissues movement, causing pressure against the pins. Constant 
motion of soft tissues around the pins prolongs the debridement phase of wound healing, and results in continual exudation of the pin track [32]. The sites where it occurs more commonly are close to the elbow and stifle joints, according to another study [15]. Wire drainage may lead to a wire tract infection. Wire and pin tract infection with sero-purulent discharge occurred in five cases (16.6\%); antibiotic therapy was established to put the infection under control. A quite common complication applying progressive lengthening of the radius-ulna is flexion contracture and antebrachiocarpal joint contracture [5, 6, 18, 20, 28, 32, 33]. Limb lengthening was performed in ten cases, and in four resulted a carpus contracture. Loss of range of motion is the consequence of the traction exerted on the flexor muscles, due to the lengthening procedure, combined with limb disuse [32]. In the antebrachium, a loss of extension is more likely than a loss of flexion, potentially because the flexor muscles have more bulk than the extensor muscles [14]. The treatment of this complication was based on physiotherapy, on the use of a stirrup with elastic bands for continuous carpal extension [28], and pain control by no steroidal antiinflammatory drugs and/or opioid analgesic drugs. This protocol should be started as soon as possible if a large lengthening is scheduled. If flexor contracture persists, the limb lengthening should be stopped even before complete correction of the length deficit is achieved [18, 28]. Usually, a minor length discrepancy between limbs is not a clinical problem. This is because of the ability of the dog to compensate for length deficits of up to $15 \%$ by extending the joints $[6,18,28]$. Wire breakage should be prevented by a frame construct stronger than the minimum required. In this case, a broken wire can be just removed, while it must be replaced when its loss can cause frame instability. In case \#6, a delayed consolidation of the regenerate and osteolysis around a threaded pin were diagnosed at the end of angular correction. The instability of the frame was thought as the most likely cause of a poor regenerate. In case \#17, a premature regenerate consolidation occurred. The premature consolidation was due to a bad management of the distraction by the owner. Using CEF technique, it is mandatory to establish a good cooperation with the owner, especially when progressive correction is to be carried out. The owner's compliance and availability can be considered a condition for inclusion of a candidate. In seven cases, a residual torsional deformity required correction in the PO period. This complication involved the only deformity that was acutely corrected in the operating room. On the contrary, progressive correction allows the surgeon to check the progression of correction while the dog is using the limb. This is a peculiar feature of the technique, and it greatly contributed in ameliorating the outcome score of the deformity treated. It represents a distinctive difference if compared to internal stabilisation or linear external fixators, where PO adjustments are not easily feasible, and usually not on three planes. An average of seven PO clinical and radiographic rechecks were performed. The results of this study suggest that CEF require a constant monitoring, and complications are quite frequent. In previous studies, the outcome for treatment of angular deformity by CEF has been reported as good or excellent in 65 to $100 \%$ of the cases [5, $6,20,28]$. In this study, radiographic outcome was classified excellent or good in twenty-nine cases (96.6\%), and functional and cosmetic outcome was classified excellent or good in twenty-eight cases (93.3\%). Residual deformities were in average 3.4 degrees (median 2.0, $\mathrm{SD} \pm 4.1$ ) for valgus and $1.65 \%$ of radial length. Simple limb deformities without shortening have been corrected successfully using linear external fixators and plates, with results comparable to those of CEF [7,11-13]. The major advantage of CEF compared to linear external fixators and bone plates is the ability to allow the correction of severe axial deformities and bone shortening, thanks to its capability to generate new tissues [5, 6, 20, 28, 30, 34].

These results were similar to residual deformities after limb deformity correction in others studies $[5,6,20]$. The technique has a steep learning curve, and constant owner's cooperation is required.

\section{CONFLICT OF INTEREST}

Dr. Gian Luca Rovesti declares to have a potential conflict of interests, having stock options of the Ad Maiora company, which produces one of the external fixation systems (Universal I) used in this case series.

Dr. Gian Luca Rovesti DVM, dipl. ECVS.

\section{REFERENCES}

[1] Meier H, Clark ST, Schnelle GB, et al. Hypertrophic osteodystrophy associated with disturbances of Vitamin C synthesis in dogs. J Am Vet Med Assoc 1957; 130(11): 483-91.

[2] Carrig CB. Growth abnormalities of the canine radius and ulna. Vet Clin North Am Small Anim Pract 1983; 13(1): 91-115.

[3] Fox SM. Premature closure of distal radial and ulnar physes in dog. Part I. Pathogenesis and diagnosis. Compend Contin Educ Pract Vet 1984; 6(2): 128-39.

[4] Malik R, Laing C, Davis PE, et al. Rickets in a litter of racing greyhounds. J Small Anim Pract 1997; 38 (3): 109-14.

[5] Marcellin-Little DJ, Ferretti A, Roe SC, et al. Hinged Ilizarov external fixation for correction of antebrachial deformities. Vet Surg 1998; 27(3): 231-45.

[6] Theyse LFH, Voorhout G, Hazewinkel HAW. Prognostic factors in treating antebrachial growth deformities with a lengthening procedure using a circular external skeletal fixation system in dogs. Vet Surg 2005; 34(5): 424-35.

[7] Quinn MK, Ehrhart N, Johnson AL, et al. Realignment of the radius in canine antebrachial growth deformities treated with corrective osteotomy and bilateral (type II) external fixation. Vet Surg 2000; 29(6): 558-63.

[8] Boudrieau RJ. Fractures of the radius and ulna. In: Slatter WB, Ed. Textbook of small animal surgery. $3^{\text {rd }}$ ed. Philadelphia, PA: Saunders, 2003; pp. 1953-73.

[9] Johnson JA, Austin C, Breur GJ. Incidence of canine appendicular musculoskeletal disorder in 16 veterinary teaching hospitals from 1980 to 1989. Vet Comp Orthop Traumatol 1994; 7(2): 56-69.

[10] MacDonald JM, Matthiesen D. Treatment of forelimb growth plate deformity in 11 dogs by radial dome osteotomy and external coaptation. Vet Surg 1991; 20(6): 402-8.

[11] Forell EB, Schwartz PD. Use of external skeletal fixation for treatment of angular deformity secondary to premature distal ulnar physeal closure. J Am Anim Hosp Assoc 1993; 29(5): 460-76.

[12] Fox SM, Bray JC, Guerin SR, et al. Antebrachial deformities in the dog: treatment with external fixation. J Small Anim Pract 1995; 36(7): 315-20.

[13] Balfour RJ, Boudrieau RJ, Gores BR. T-plate fixation of distal radial closing wedge osteotomies for treatment of angular limb deformities in 18 dogs. Vet Surg 2000; 29 (3): 207-17.

[14] Marcellin-Little DJ. Alternative to the circular external fixator for antebrachial deformity correction. In: Vezzoni A, Schramme M, Eds. Proceedings of the $12^{\text {th }}$ European Society of Veterinary Orthopaedics and Traumatology Congress, September $10^{\text {th }}-12^{\text {th }}$ Munich, Germany, 2004; pp. 91-3.

[15] Marcellin-Little DJ. Complications of circular external fixator. In: Proceedings of the $12^{\text {th }}$ European Society of Veterinary 
Orthopaedics and Traumatology Congress, September $10^{\text {th }}-12^{\text {th }}$ Munich, Germany, 2004; pp. 105-7.

[16] Fox DB, Tomlinson JL, Cook JL, et al. Principles of uniapical and biapical radial deformity correction using dome osteotomies and the center of rotation of angulation methodology in dogs. Vet Surg 2006; 35(1): 67-77.

[17] Aronson J. Biology of distraction osteogenesis. In: Bianchi Maiocchi A, Aronson J, Eds. Operative principles of Ilizarov. Fracture Treatment - Nonunion - Osteomyelitis - Lengthening Deformity Correction. Milan, Italy, Medi Surgical Video, 1991; pp 42-51.

[18] Latte Y. Application of the Ilizarov method in veterinary orthopaedic surgery (part 1). Eur J Comp Anim Pract 1997; 7(2): 26-50.

[19] Stallings JT, Lewis DD, Welch RD, et al. An introduction to distraction osteogenesis and the principles of the Ilizarov method. Vet Comp Orthop Traumatol 1998; 11(2): 59-67.

[20] Lewis DD, Radasch RM, Beale BS, et al. Initial clinical experience with the IMEX ${ }^{\mathrm{TM}}$ circular external skeleton fixation system. Part II: Use in bone lengthening and correction of angular and rotational deformities. Vet Comp Orthop Traumatol 1999; 12(2): 118-27.

[21] Benedetti GB, Argnani F. Deformity corrections (hinges and fulcrums). In: Bianchi Maiocchi A, Aronson J, Eds. Operative principles of Ilizarov. Fracture Treatment - Nonunion Osteomyelitis - Lengthening - Deformity Correction. Milan, Italy, Medi Surgical Video, 1991; pp. 73-7.

[22] Lesser AS. Ilizarov Technique. In: Bojrab MJ, Ellison GW, Slocum B. Ed. Current techniques in small animal surgery. $4^{\text {th }}$ ed. Baltimore, Maryland, USA 1998; pp. 950-63.

[23] Monticelli G, Spinelli R. Distraction epiphysiolysis as a method of limb lengthening. I. Clinical applications. Clin Orthop Relat Res 1981; 154(2): 254-61.

[24] Monticelli G, Spinelli R. Distraction epiphysiolysis as a method of limb lengthening. II. Morphologic investicgations. C Clin Orthop Relat Res 1981; 154(2): 262-73.
[25] Monticelli G, Spinelli R. Distraction epiphysiolysis as a method of limb lengthening. III: Clinical applications. Clin Orthop Relat Res 1981; 154(2): 274-85.

[26] De Bastiani G, Aldegheri R, Renzi Brivio L, et al. Limb lengthening by distraction of the epiphyseal plate: a comparison of two techniques in the rabbit. J Bone Joint Surg Br 1986; 68(4): 545-9.

[27] Tsuchiya H, Tomita K. Ilizarov application for tumor reconstruction. In: Catagni MA, Bianchi Maiocchi A, Eds. Treatment of fractures, nonunions, and bone loss of the tibia with the ilizarov method. Including war injuries and tumor resection. Milan, Italy, Medi Surgical Video, Departiment of Medicalplastic s.r.1., 1998; pp. 195-204.

[28] Latte Y. 75 applications of the Ilizarov method (part 2). Eur J Comp Anim Pract 1998; 8(1): 64-81.

[29] Rovesti GL, Schmidt K, Margini A. Fourteen cases of angular deformities in dog corrected by means of the Ilizarov technique. May S, Houlton JF, Eds. Proceedings of the $10^{\text {th }}$ European College Veterinary Surgeons Congress, July $6^{\text {th }}-8^{\text {th }}$ Velbert, Germany 2001; p. 297.

[30] Ferretti A, Faranda C, Monelli M. Il metodo di Ilizarov: un nuovo trattamento delle deviazioni e della dismetria del radio e ulna. Veterinaria 1987; 1(1): 57-60.

[31] Ferretti A. The application of the Ilizarov technique to veterinary medicine. In: Bianchi Maiocchi A, Aronson J, Eds. Operative principles of Ilizarov. Fracture Treatment - Nonunion Osteomyelitis - Lengthening - Deformity Correction. Milan, Italy, Medi Surgical Video, 1991; pp. 551-70.

[32] Aron DN, Dewey CW. Application and postoperative management of external skeletal fixators. Vet Clin North Am Small Anim Pract 1992; 22(1): 69-97.

[33] Lesser AS. Segmental bone transport for treatment of bone deficits. J Am Anim Hosp Assoc 1994; 30(4): 322-30.

[34] Marcellin-Little DJ. External skeletal fixation. In: Slatter WB, Ed. Textbook of small animal surgery/ $3^{\text {rd }}$ ed. Philadelphia, PA: Saunders 2003; pp. 1818-34. 